\title{
Common Hazards Associated with Sheep and Goat Feed $^{1}$
}

\author{
Chalise Brown, Diwakar Vyas, and Jason M. Scheffler ${ }^{2}$
}

\section{Introduction}

The Food Safety Modernization Act (FSMA) was signed into law in January of 2011. FSMA attempts to shift the focus of food safety from reacting to foodborne outbreaks to preventing them from occurring. The law stipulates that complying facilities that manufacture, process, pack, or hold food (hereafter referred to as feed) or feed ingredients for animals must implement Hazard Analysis and Risk-Based Preventive Controls, or HARPC (FDA 2018a; Scheffler and Carr 2016). Hazard Analysis and Risk-Based Preventive Controls have similarities to the Hazard Analysis and Critical Control Points (HACCP) that are commonly used in foods for humans, such as meat, seafood, and juice, but may be unfamiliar to facilities producing feed for livestock. For more information on compliance requirements and the general structure of an animal food safety plan, consult EDIS document AN330, The Food Safety Modernization Act (FSMA) Preventive Controls for Animal Food (https://edis.ifas.ufl.edu/an330).

The first step in writing a food safety plan is to conduct a hazard analysis. Hazards are divided into biological, chemical (including radiological), and physical categories that are known to be, or have the potential to be, associated with the facility or the animal food. A thorough hazard analysis should identify potential hazards as well as their frequency and severity in order to determine the methods for prevention. In many cases, a facility's compliance with written Current Good Manufacturing Practices (CGMPs) and Standard Operating Procedures (SOPs) can prevent hazards. However, some hazards require more robust preventive controls. The determination of whether a hazard requires a preventive control depends on the hazard's frequency and severity, which vary based on the facility and species being fed. This document provides a list of common hazards to consider in the manufacturing of feed for small ruminants. This is not a comprehensive list. A thorough hazard analysis performed by a preventive controls qualified individual (PCQI) is required to identify hazards for each facility. For more information about PCQIs, visit https://edis.ifas.ufl.edu/an330.

\section{Why is it important to prevent hazards from occurring in animal feed?}

The Federal Food, Drug, and Cosmetic Act requires that "all animal food, including human food, be safe to eat, produced under sanitary conditions, contain no harmful substances, and be truthfully labeled" (FDA 2018b). The animal and pet food manufacture is a multibillion-dollar industry that experiences recalls every year due to food safety hazards. The average cost of a recall to a food company is $\$ 10$ million and includes losses directly associated with the affected food as well as lost sales and brand damage (Grocery Manufacturers Association 2010).

1. This document is AN363, one of a series of the Department of Animal Sciences, UF/IFAS Extension. Original publication date November 2020. Visit the EDIS website at https://edis.ifas.ufl.edu for the currently supported version of this publication.

2. Chalise Brown, student, Department of Animal Sciences; Diwakar Vyas, assistant professor, Department of Animal Sciences; and Jason M. Scheffler, research assistant professor, muscle biology, Department of Animal Sciences; UF/IFAS Extension, Gainesville, FL 32611.

The Institute of Food and Agricultural Sciences (IFAS) is an Equal Opportunity Institution authorized to provide research, educational information and other services

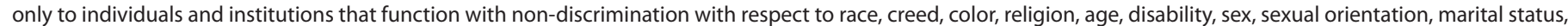

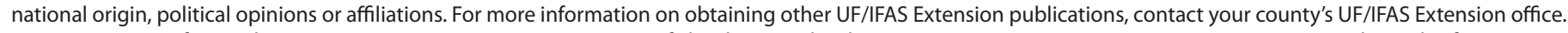
U.S. Department of Agriculture, UF/IFAS Extension Service, University of Florida, IFAS, Florida A \& M University Cooperative Extension Program, and Boards of County Commissioners Cooperating. Nick T. Place, dean for UF/IFAS Extension. 
In some cases, the recall may be such a financial burden that companies cannot recover from it. However, the implication of food safety hazards goes beyond economics. Food safety hazards in animal feed can also cause risks to humans. For example, aflatoxins can be consumed by dairy goats and released into the milk. These can cause damage to the urinary, digestive, nervous, and reproductive systems in humans (Mukherjee 2012).

\section{What are the common physical hazards to consider?}

Physical hazards include stones, glass, metal, wood, plastic, or any physical object that could enter the feed and cause harm. Harvesting and processing cattle feed require machinery, equipment, and processes that can unintentionally introduce physical hazards. Broken parts and shards of metal could be mixed into feed ingredients. A poorly located and unprotected light bulb has a risk of shattering. Tools, cell phones, glasses, and other objects may be misplaced or fall into processing equipment and become physical hazards in the feed.

The frequency and severity of a physical hazard depend on each facility and process. A facility might choose to utilize a magnet or a screen to remove contaminants as part of its SOPs to reduce the frequency of the hazard. In addition, shatterproof bulbs can be strategically located to reduce the risk of glass contamination. Standard Operating Procedures for handling tools and personal effects can mitigate risk of those objects becoming physical hazards. Each facility should take into account the source of ingredients, product flow, equipment, storage, and packaging to determine the points where physical hazards could enter the product as well as the appropriate measures to prevent them.

\section{What are the biological hazards to consider?}

Unlike food for humans, the list of bacterial hazards for livestock species is relatively short. Nevertheless, animal feed is a potential carrier for a wide variety of microorganisms. Two serotypes of Salmonella are a major biological hazard to consider when producing sheep and goat feed because they can cause severe symptoms, including abortion. The strains known to cause reproductive losses in sheep and goats include $S$. Typhimurium, S. Dublin, $S$. Abortusovis, and S. Montevideo (Iowa State University 2017). S. Typhimurium and $S$. Montevideo have a prevalence of $5.4 \%$ and $8.9 \%$ in feeds, respectively (Li 2012). The other two serotypes, $S$. Dublin and $S$. Abortusovis, do not have an appreciable prevalence in feed (Li 2012). While these studies suggest that the risk for disease in humans and animals caused by Salmonella is relatively low, each facility should perform a risk assessment to determine the likelihood and severity of an outbreak. Regardless, it is important to keep feed dry, to control dust and pests, and to ensure that trucks transporting feed and its ingredients are properly cleaned in order to prevent contamination.

Listeriosis is primarily a winter-spring disease of feedlot or housed ruminants (Scott 2019). When making ensiled feeds, be sure to limit soil contamination and discard spoiled feeds because the less acidic $\mathrm{pH}$ can result in the growth of Listeria monocytogenes (Scott 2019). Listeriosis can result in abortion, septicemia (disease causing bacteria in the bloodstream), or meningoencephalitis (inflammation of the nervous system) (Scott 2019). Listeria monocytogenes is a potential pathogen in silage because of its ability to compete in low-oxygen and high-moisture environments. The presence of L. monocytogenes in feed is enough to induce clinical symptoms in sheep and goats (Nightangle et al. 2004). Silages that were linked to listeriosis in sheep were reported to contain $10^{6}$ cells/g fresh matter (Fernandez-Garayzabal et al. 1992).

Botulism is a fatal disease characterized by paralysis followed by organ failure. It is most often caused by the Clostridium botulinum toxin (Stämpfli 2019). In anaerobic conditions such as in decaying carcasses or vegetation, $C$. botulinum can produce toxins, which are then ingested by the animal (Stämpfli 2019). Botulism is rarely an issue in the United States, but it may occur when the silage fermentation process fails to reach a stable pH below 4.5 (Stämpfli 2019). It is more likely to occur if the animal eats carrion to compensate for a carbohydrate or protein deficiency (Stämpfli 2019).

\section{What are the chemical hazards to consider?}

\section{Naturally Occurring}

Mycotoxins are toxins produced by various fungi and molds. These can occur in moldy feeds exposed to hot conditions. Therefore, good management practices are key to controlling this hazard. The most common mycotoxins are aflatoxin B1, fumonisin B1, zearalenone, ochratoxin, vomitoxin, T-2, and HT-2.

Aflatoxins (product of the mold fungus Aspergillus flavus, Aspergillus parasiticus, and Aspergillus nomius) are the mycotoxin of primary concern. They are found in various 
feed ingredients including corn, cottonseed, and peanuts. Sheep and goats are resistant to acute aflatoxin toxicity but are still susceptible if they consume contaminated diets over time (Osweiler 2019). Humans face the higher threat because aflatoxins pass to the meat and milk of the animal, which humans might ingest. The toxic effects of aflatoxins include mutagenesis, carcinogenesis, teratogenesis, reduced protein synthesis, and immunosuppression (Osweiler 2019). Furthermore, the action limit for aflatoxins in sheep and goat feeds is only $20 \mathrm{ppb}$ (FDA 1994). Hot and dry climates encourage the production of aflatoxins. Extra precautions should be taken when these weather conditions persist in areas where the feedstuff is grown and stored (Osweiler 2019).

Best management practices are crucial in the control of mycotoxins. They are meant to prevent production of mycotoxins and to inactivate toxins that may already be present in feed. Testing of ingredients upon arrival, maintaining clean and dry storage facilities, using acid additives to control mold growth in storage, ensuring effective air exclusion in silage storage, and using first-in-first-out protocols are established procedures to prevent mycotoxin formation. Acidic additives control mold growth but do not destroy toxins that have already formed (Osweiler 2019).

Antinutrients are common substances found in animal feed and water. These substances (e.g., gossypol, glucosinolates, erucic acids, and alkaloids) may reduce the availability of nutrients, impair animal production and reproduction, and compromise animal immune systems. Cottonseed is a common source of gossypol (Morgan 2017). Glucosinolates occur in plants of the Brassica genus of the mustard family, including cabbage, broccoli, rapeseed, and carinata. Rapeseed (canola) and carinata meal can be used as livestock feed, but the presence of glucosinolates needs to be considered in a risk assessment (Schulmeister et al. 2019; Scientific Panel on Contaminants in the Food Chain 2008). Caution is advised when using new alternative feed ingredients or industrial by-products that may contain high levels of antinutrients. Tannins can reduce protein availability, lower palatability, and may induce systemic toxicity (Makkar 2003). Condensed tannins such as Quebracho may induce epithelial degeneration and gut ulceration, resulting in lower DM and protein digestibility (Dawson et al. 1999).

Undeclared allergens are the leading cause of recalls in human food (FDA 2016). However, allergens are not considered a serious hazard in animal feed. Generally, allergies may manifest themselves as dermatitis in animals rather than the severe allergic reactions observed in humans. No serious adverse effects of allergens in animal food have been reported to the Reportable Food Registry from 2009 to 2014 (FDA 2016).

\section{Unintentionally Introduced}

Unintentionally introduced chemical hazards include pesticides, drug residues, and nutrient deficiencies or toxicities.

Because many crops used as animal feed ingredients are treated with pesticides and other chemicals to ensure acceptable or desired yields, they may contain chemical residues. In addition, the processes of harvesting and manufacturing expose feedstuffs to possible contamination by petroleum-based greases and other chemicals. These residues can pose risks to animals as well as humans due to the accumulation of these products in fat tissues. The FDA Pesticide Monitoring Program suggests that very few animal feeds contain residues that exceed permitted levels (FDA 2018c). More information about pesticide residues in animal feedstuffs can be found in the Compliance Policy Guide Sec. 575.100 Pesticide Residues in Food and Feed (FDA 2018d). The likelihood of introduction of these chemicals to feedstuffs should be determined during a hazard analysis, and appropriate prevention methods should be implemented.

Drug residues are best controlled by following manufacturers' instructions and using appropriate sequencing methods to prevent the contamination of other feeds. Ionophores are of particular concern. Monensin is approved for use with goats (FDA 2019). However, ionophores can be toxic to sheep in excessive doses (11.9 ppm in the case of monensin [Confer, Reavis, and Panciera 1983]. Horses are the most sensitive to ionophores; traces of the drug (2-3 ppm) can result in death (Ordidge, Schubert, and Stoker 1979). Therefore, when mixing feed for ruminants, it is important to be conscientious of this risk, especially if the feed mill also formulates rations for horses.

Sequencing of the manufacture and handling of medicated feeds as a method of preventing unsafe contamination is listed and may be done under 21 CFR 225.165. If properly planned and executed, it may be the most practicable manner of dealing with the drug carryover problem under the current state of feed manufacturing technology. Sequencing is defined as the preplanned order of production, storage, and distribution of different animal feeds designed to direct drug carryover into subsequent feeds that will not result in unsafe contamination. The highest level of drug contamination following a medicated feed occurs in the subsequent 
batch of feed handled or processed in the equipment (FDA 2015).

All medicated animal feed must be manufactured and distributed in compliance with Current Good Manufacturing Requirements of Medicated Feeds (FDA 2018a). It is important to note that feed additives containing medically important antimicrobials may fall under the Veterinary Feed Directive (VFD). The VFD brings therapeutic uses of drugs under veterinary supervision and requires a prescription to use medically important drugs in feed or water of food-producing animals. For more information about which feed additives may fall under the VFD, visit the FDA website (FDA 2015b).

The use of drugs in feed in an extra-label manner (outside of label recommendations) in sheep and goats is under the guidance of the FDA Center of Veterinary Medicine (CVM) and should only be done with a prescription from a veterinarian. The compliance policy suggests that regulatory action against veterinarians, producers, or feed mills will not be considered if the medicated feed is only for the use of sheep and goats; if medicated feed for sheep and goats is approved for use in horses, cattle, pigs, dogs, cats, chickens, and turkeys and formulated according to its approved labeling (dose, nutrient content); or if feed is limited to farmed or confined sheep and goats. In addition, veterinarians must establish withdrawal time and maintain the identity of treated animals. Producers must maintain accurate feed records for at least one year from feed delivery, and must maintain the identity of the treated animal (Fajt 2011).

Nutrient toxicity is the most common hazard considered when mixing feed for sheep. This type of toxicity occurs due to mixing and/or formulating rations improperly. Copper is a highly severe hazard for sheep because toxicity can occur easily, and the results are fatal. Generally, sheep need between 4-8 ppm of copper in their diet, and toxicity may occur at $20 \mathrm{ppm}$ (Pugh 2019). A sufficient amount of molybdenum and sulfate in the diet increases the amount of copper sheep can tolerate, but it is still important to ensure that the amount of copper in sheep feed does not approach levels that could result in toxicity (Pugh 2019). The Cu:Mo ratio should be maintained between 5:1 and 10:1 (Pugh 2019). Regardless, sheep should not be given any feed intended for other species (i.e., reworked feed should not be incorporated into sheep feeds).

Goats are generally more tolerant to copper. Due to the high severity and variable frequency, each facility should determine if a preventative control is necessary by performing a risk assessment that identifies the likelihood of copper toxicity. The toxic level of $\mathrm{Cu}$ for sheep is not observed with goats. Copper requirements of goats range from 15 ppm for lactating does, to $20 \mathrm{ppm}$ for mature goats, and 25 ppm for growing goats considering normal Mo (1-2 ppm) and S (0.15\%-0.25\%) intakes (NRC 2007). Based on NRC (2007) recommendations, the maximum tolerable level for $\mathrm{Cu}$ in goats is $40 \mathrm{ppm}$. It is not advisable to utilize the same mineral supplement for both goats and sheep. The toxicity level of copper for sheep and the deficiency level for goats provide a slim margin of error.

Selenium is a nutrient that is necessary in the prevention of white muscle disease, but it may also be toxic in excess (Pugh 2019). Feed supplements generally should have a selenium content of $0.2-0.3 \mathrm{ppm}$ and the maximum tolerable concentrations are $2-5 \mathrm{ppm}$; however, it is thought that concentrations between 4-5 ppm may inhibit growth (Hall 2019). Mild symptoms of selenium toxicity occur when concentrations exceed 5 ppm over 30 days. Concentrations between 10-25 ppm would cause severe symptoms of toxicity (Hall 2019).

\section{Nutrient Deficiency}

McDowell and Tiffany (1998) indicated deficiencies of phosphorus, calcium, sodium, magnesium, cobalt, copper, and zinc in Florida cattle, primarily due to low levels of these minerals in pasture and soil. However, there is still a lack of studies on the impact of mineral deficiencies for sheep and goat production in Florida.

Two notable mineral deficiencies to consider in sheep and goats are zinc and cobalt. Growing lambs need approximately $30 \mathrm{ppm}$ of zinc in the diet to prevent deficiency. Note that goats are more susceptible to zinc deficiency (parakeratosis), but it may also occur in sheep.

Cobalt is an essential trace mineral required for the synthesis of vitamin $\mathrm{B}_{12}$. Rumen microorganisms use dietary cobalt from soil and pasture to synthesize this vitamin. Forages in Florida are generally deficient in cobalt. Therefore, supplements need to include adequate amounts of cobalt to avoid vitamin $B_{12}$ deficiency (Chelliah et al. 2008). The symptoms of vitamin $B_{12}$ deficiency include loss of appetite, lower growth rates, weight loss, and anemia. Young growing lambs are prone to vitamin $\mathrm{B}_{12}$ deficiency due to their higher energy requirement for growth. In addition, pregnant ewes deficient in vitamin $\mathrm{B}_{12}$ may have lower lambing percentages and are at greater risk of metabolic diseases. 


\section{Intentionally Introduced}

Intentionally introduced chemical hazards can be any of the aforementioned hazards that are introduced to feedstuffs for economic gain or sabotage. The most well-known example of a chemical hazard intentionally introduced for economic gain is melamine in pet food. Melamine is a nitrogen-rich compound that artificially inflates the crude protein content of a feedstuff upon analysis. Intentionally introduced hazards are difficult to predict and should be considered when reviewing CGMPs and SOPs to reduce the risks. See the FSMA Final Rule for Mitigation Strategies to Protect Food against Intentional Adulteration for more recommendations (FDA 2018e).

\section{How do I prevent these hazards from occurring?}

There are multiple ways of preventing hazards from occurring in cattle feed. Appropriate methods of prevention depend on the hazard, its severity, and its likelihood of occurring. Robust CGMPs and SOPs are in practice in most facilities, and many already work to prevent hazards. However, there are some hazards that require more intense methods of prevention due to their severity or frequency.

Some facilities implement preventive controls, or additional actions taken to ensure the prevention of certain hazards, and their required components (FDA 2018a). There are four forms of preventive controls: process controls, sanitation controls, supply-chain or supplier controls, and other controls (FDA 2018a). Process controls are the most prevalent in a livestock feed facility. They may include batching and sequencing procedures and daily reconciliation of specific ingredients (e.g., sources of copper and antibiotics such as monensin).

The decision to use CGMPs and SOPs or preventive controls to control hazards is dependent on each facility and hazard. Note that decisions regarding methods of prevention require documented and thorough justification. Justification should be based on facility experience, illness data, scientific reports, and FDA resources.

\section{Additional Information}

FDA (key requirements for preventive controls for animal feed): http://www.fda.gov/downloads/Food/GuidanceRegulation/FSMA/UCM461884.pdf

FDA (FSMA; animal feed overview): http://www.fda. gov/AnimalVeterinary/Products/AnimalFoodFeeds/ ucm347941.htm
UF/IFAS Department of Animal Sciences (FSMA): http:// animal.ifas.ufl.edu/FSMA/index.shtml

Food Safety Preventive Controls Alliance (FSPCA): https:// www.ifsh.iit.edu/fspca

Southern Center for FSMA Training: http://sc.ifas.ufl.edu/

\section{References}

Chelliah, G., R. O. Myer, J. N. Carter, L. R. McDowell, and N. S. Wilkinson. 2008. "Mineral Concentrations of Cool Season Pasture Forages in North Florida during the WinterSpring Grazing Season: II. Trace Minerals." Journal of Plant Nutrition 31 (10).

Confer, A. W., D. U. Reavis, and R. J. Panciera. 1983. "Light and Electron Microscopic Changes in Cardiac and Skeletal Muscle of Sheep with Experimental Monensin Toxicosis." Veterinary Pathology 20 (5): 590-602. https:// doi.org/10.1177/030098588302000511

Dawson, J. M., P. J. Buttery, D. Jenkins, C. D. Wood, and M. Gill. 1999. "Effects of Dietary Quebracho Tannin on Nutrient Utilization and Tissue Metabolism in Sheep and Rats." Journal of Science of Food and Agriculture 79:1423-1430.

Fajt, V. R. 2011. "Drug Laws and Regulations for Sheep and Goats." Veterinary Clinics of North America: Food Animal Practice 27:1-21.

FDA. 1994. "FDA Compliance Policy Guide Sec. 683.100 Action Levels for Aflatoxins in Animal Feeds." Accessed April 27, 2019. https://www.fda.gov/ regulatory-information/search-fda-guidance-documents/ cpg-sec-683100-action-levels-aflatoxins-animal-feeds

FDA. 2015a. "CPG Sec. 680.600 Sequencing as a Means to Prevent Unsafe Drug Contamination in the Production, Storage, and Distribution of Feeds." Accessed April 20, 2019. https://www.fda.gov/regulatory-information/searchfda-guidance-documents/cpg-sec-680600-sequencingmeans-prevent-unsafe-drug-contamination-productionstorage-and

FDA. 2015b. "Veterinary Feed Directive; Final Rule." Accessed March 17, 2019. https://www.govinfo.gov/content/ pkg/FR-2015-06-03/pdf/2015-13393.pdf

FDA. 2016. "The Reportable Food Registry: A Five Year Overview of Targeting Inspection Resources and Identifying Patterns of Adulteration." Accessed April 27, 2019. https://www.fda.gov/media/97862/download 
FDA. 2018a. "CFR—Code of Federal Regulations

Title 21.” Accessed April 27, 2019. https://www.accessdata.fda.gov/scripts/cdrh/cfdocs/cfcfr/CFRSearch. $\mathrm{cfm}$ ?CFRPart=225\&showFR=1

FDA. 2018b. "Pet Food." Accessed April 27, 2019. https:// www.fda.gov/animalveterinary/products/animalfoodfeeds/ petfood/default.htm

FDA. 2018c. "Pesticide Residue Monitoring Program Reports and Data." Accessed April 27, 2019. https://www.fda.gov/food/pesticides/ pesticide-residue-monitoring-program-reports-and-data

FDA. 2018d. “Compliance Policy Guide Sec. 575.100 Pesticide Residues in Food and Feed-Enforcement Criteria (Compliance Policy Guide 7141.01)." Accessed April 27, 2019. https://www.fda.gov/regulatory-information/ search-fda-guidance-documents/compliance-policy-guidesec-575100-pesticide-residues-food-and-feed-enforcementcriteria-compliance

FDA. 2018e. "FSMA Final Rule for Mitigation Strategies to Protect Food against Intentional Adulteration." Accessed April 27, 2019. https://www.fda.gov/food/food-safetymodernization-act-fsma/fsma-final-rule-mitigationstrategies-protect-food-against-intentional-adulteration

FDA. 2019. "FDA Approves First Generic Monensin for Use in Cattle and Goats, Reminds Users of Toxicity for Horses." https://www.fda.gov/animal-veterinary/cvm-updates/ fda-approves-first-generic-monensin-use-cattle-and-goatsreminds-users-toxicity-horses

Fernandez-Garayzabal, J. F., M. Blanco, J. A. Vazquez-Boland, V. Briones, J. A. Garcia, C. Delgado, M. Domingo, and L. Dominguez. 1992. "A Direct Plating Method for Monitoring the Contamination of Listeria monocytogenes in Silage." Journal of Veterinary Medicine 39 (1-10): 513-518. https://doi.org/10.1111/j.1439-0450.1992.tb01200.x

Grocery Manufacturers Association. 2010. "Recall Execution Effectiveness: Collaboration Approaches to Improving Consumer Safety and Confidence." Accessed April 27, 2017. https://www.gmaonline.org/downloads/research-andreports/WP_RecallExecution.pdf

Hall, J. 2019. "Overview of Selenium Toxicosis." The Merck Veterinary Manual. Accessed February 20, 2019. https:// www.merckvetmanual.com/toxicology/selenium-toxicosis/ overview-of-selenium-toxicosis?query=selenium $\% 20$ sheep
Iowa State University. 2017. "Salmonella Abortusovis." Retrieved March 15, 2019. http://www.cfsph.iastate.edu/ Factsheets/pdfs/salmonella_abortusovis.pdf

Li, X., L. A. Bethune, Y. Jia, R. A. Lovell, T. A. Proescholdt, S. A. Benz, T. C. Schell, G. Kaplan, and D. G. McChesney. 2012. "Surveillance of Salmonella Prevalence in Animal Feeds and Characterization of the Salmonella Isolates by Serotyping and Antimicrobial Susceptibility." Foodborne Pathogens and Disease 9 (8).

Morgan, S. E. 2017. "Gossypol Toxicity in Livestock." Oklahoma Cooperative Extension Fact Sheets. http://pods. dasnr.okstate.edu/docushare/dsweb/Get/Document-1952/ VTMD-9116-2015.pdf

Mukherjee, S. 2012. "Aflatoxin Effect on Health.” Retrieved March 1, 2019. http://www.fao.org/fileadmin/user_upload/ wa_workshop/ECAfrica-caadp/4._Aflatoxin_USAID.pdf

Ordidge, R. M., F. K. Schubert, and J. W. Stoker. 1979. "Death of Horses after Accidental Feeding of Monensin." Veterinary Record 104 (16): 375. http://dx.doi.org/10.1136/ vr.104.16.375

Osweiler, G. 2019. "Aflatoxicosis." The Merck Veterinary Manual. Accessed April 11, 2019. https://www. merckvetmanual.com/toxicology/mycotoxicoses/ aflatoxicosis?query=aflatoxins

Pugh, D. 2019. "Nutrient Requirements of Sheep." The Merck Veterinary Manual. Accessed March 5, 2019. https://www.merckvetmanual.com/ management-and-nutrition/nutrition-sheep/ nutritional-requirements-of-sheep?query=zinc\%20sheep

Scheffler, J., and C. Carr. 2016. The Food Safety Modernization Act (FSMA) Preventive Controls for Animal Food. AN330. Gainesville: University of Florida Institute of Food and Agricultural Sciences. https://edis.ifas.ufl.edu/an330

Schulmeister, T. M., M. Ruiz-Moreno, G. M. Silva, M. Garcia-Ascolani, F. M. Ciriaco, D. D. Henry, G. C. Lamb, J. C. B. Dubeux, Jr., and N. DiLorenzo. 2019. "Evaluation of Brassica carinata Meal as a Protein Supplement for Growing Beef Heifers." Journal of Animal Science 97 (10): 4334-4340. https://doi.org/10.1093/jas/skz280

Scientific Panel on Contaminants in the Food Chain. 2008. "Glucosinolates as Undesirable Substances in Animal Feed." The EFSA Journal 590:1-76. http://www.adiveter.com/ ftp_public/A4150208.pdf 
Scott, P. 2019. "Overview of Listeriosis." The Merck

Veterinary Manual. Accessed March 20, 2019. https://www. merckvetmanual.com/generalized-conditions/listeriosis/ overview-of-listeriosis

Stämpfli, H. 2019. “Botulism.” The Merck Veterinary

Manual. Accessed March 20, 2019. https://www.merckvetmanual.com/generalized-conditions/clostridial-diseases/ botulism?query=botulism 